\title{
How to Survive with Various Sets of Ethical Values
}

\author{
By Eduardo V. López ${ }^{*}$
}

The repetition of governance fiascos made it necessary to reassess the fundamentals of what have up till now been considered to be undisputable knowledge. As outdated governance practices are incapable to cope with the challenge presented by the struggle between business and society ethics, the sources of deviance need to be identified to adopt new governance approaches able to drive simultaneously business success and social responsibility. This paper highlights the existence of various sets of ethical values that people pick for different contexts, and that interact with other factors such as personal interests, allegiances, and opportunity. This process is depicted by the ethics cube. The shuffling of this cube disturbs professional ethics by presenting characteristics such as selfishness, idealism, and pragmatism into the picture. The outline of two new concepts: The Small Sins Allowed (a level below which adherence to ethical standards is not anticipated), and the Line of Impunity (the judgment that privileges are permitted for upper ranks), help to understand the mechanics of shifting ethical values. (JEL G30, G41, Z13)

Keywords: Ethics Cube, Line of Impunity, Small Sins allowed, Various Sets of Ethical Values.

\section{Introduction}

It is generally accepted that parental examples, religious teaching, early socialization at school and other get-together settings (sports, street, clubs, parties, etc.), along with the legal system, are constituents of universal and local beliefs that shape individual ethics. Linking the ethical attitude of the individual with the standards of a group has always been thought-provoking because group ethics requires conformity with the shared values of the majority. As different groups might have dissimilar ethical standards, moral relativism admits that it is incorrect to assume that the same ethical framework applies to all of them. The presence of cultural alterations and varied perceptions of moral intensity (Jones 1991) lead to a subjective field where several ethical mentalities have dissimilar tolerance for irregular behaviors. When Friedman (1970: 32) presented the idea of rules of the game, saying that "there is one and only one social responsibility of business... to increase its profits", business ethics differentiated itself from their player's individual ethics. Supporting this particular group's ethics, even when it might imply deviant or anomic behaviors, was driven in some cases by the need of belongingness and in other instances compelled by personal ambitions, still when the logic of this economic conception undermined the values embraced by the society at large.

\footnotetext{
*Assistant Professor of Management, Belmont University, USA.
} 
Ethical issues in business may be associated to values, rights, operations, deliverables, society, and government. Some shared views discuss unsafe product and workplace, infringement of labor regulations, discrimination, unfair treatment of minorities and women, harassment, environmental issues, product quality, theft, fraud, bribery, embezzlement, absenteeism, conflict of interests, unethical decision making, withdrawal, vandalism, sabotage, taking unfair advantages, buying influence, privacy, security of company records, appropriation of other's ideas, deceptive sales practices, rule violation, misguiding advertisement, corporate social responsibility, ideology, attitudes, and stakeholder management.

Corporate anomie and deviance are associated with characteristics such as double standards, absence of accountability, privilege to bend the rules, a feeling of being above others, and the rationalization that everybody else does it. With perceptions affected by circumstantial variables, economic and group values tend to relax the logic of morality such that some social strata join nonconformist conducts, increasing the tolerance level toward rule violations and allowing for devious behaviors to be disregarded. Brooks (2012: A23) noted that "the value of success substituted the value of virtue. As striving aggressively for success is encouraged by our customs, many people are compelled by determination to succeed at all cost, even by sacrificing ethics". Accent on outcomes make public accept as true that, without examination of principles, success is never wrong, while failure always is.

Renz (2007: 45) warned about the presence of "a gap in an integrative and complete institutionalization of the ethical discourse" when ethical issues are not discussed, analyzed, and meditated upon, when the experiences are not shared, and when the ethical considerations of policy development are not explained. Bandura et al. (1996: 365) sustained that "people do not ordinarily engage in reprehensible conduct until they have justified to themselves the rightness of their actions". Sykes and Matza (1957: 22) explained that the means used to do that are known as moral neutralization techniques (denial of responsibility, denial of victim, denial of injury, condemnation of condemners, and appeal to a higher loyalty). Consequently, any governance system must encourage a culture where shots at neutralization are not consented, generating an inner communication atmosphere that permits employees to speak up when meeting moral challenges, as muteness is a partner of neutralization.

As ethics designates actions that are right or wrong in unambiguous contexts and circumstances, it was detected that individuals could have as least two different brains or "sets of ethical values." Related to their individual ethics, Ariely (2009: 99) alleged that "even the most brilliant and rational person, in the heat of passion, seems to be absolutely and completely divorced from the person he thought he was". In the case of group ethics, individuals could have a professional brain and a social brain to apply discretionary according to the situation. Ludlow (2013: 2) postulated that "the mid-level managers... in the context of their jobs, had a separate moral code altogether". Ferrell et al. (2019: 138) highlighted the difference between moral philosophy and business ethics, sustaining that while the first is an individual person-specific choice of principles and values, the second comprises decisions made by groups performing duties aimed to meet business 
objectives in accordance to what the organization defined as correct or incorrect activities that relate to its corporate operations. Facing diverse settings, individuals may have even more than two brains. Lopez (2016: 366) found evidence of subgroups across organizational ranks.

\section{Methodology}

This study is framed by a set of beliefs, assumptions, and values that define its research paradigm elements as follows:

Ontologically it is attached to subjectivism, as it views reality as socially constructed, created from perceptions and collective interactions.

Epistemologically it is aligned with constructivism, adopting a relativistic stance by supporting the existence of multiple realities. Reality is assumed as individually constructed.

Induction is the research approach in which its methodology is founded, as the analysis of the data, considering the context of the events, piloted to the formulation of the theory in such a way that the knowledge claims contained in the conclusions were not inferred in the premises. It was used an adaptation of the Sekaran's (2003) research process for applied and basic research.

The investigation entailed two phases; in the first one (qualitative) two focus groups helped on the development of the hypotheses, while in the second one (quantitative) a survey was used to test the hypotheses using participants from professional and academic networks. This multimethod approach followed the premises mentioned by Sobh and Perry (2006) that recommend the building of the conceptual framework using one method and its substantiation by means of a different technique.

\section{Findings}

\section{The Small Sins Allowed and the Line of Impunity}

In an attempt to explain the roots of corporate anomie and deviance, Lopez (2016: 233) has defined two new constructs. The first one, Small Sins Allowed (SSA), represents "a subjective mental model that establishes the level of certain behaviors above which adherence to ethical standards is expected. It can also be thought of as the ethical tolerance level that splits any dimension into two domains; above this level there are ethical standards to comply with and abide by, whereas below it there are no ethical concerns. This level represents a limit to the freedom of deviating deliberately from customary ethical behaviors and normally applicable rules and practices. No evil in the sense of morally objectionable behavior such as immorality, iniquity, malevolence, or viciousness is perceived below this level, where actions may be perceived by some as insignificant, minimized, understated, or belonging to the domain of permissiveness". 
Behaviors that fall under the SSA are excused of any moral connotation, laying between compliance and laxity as socially tolerated. Aligned with this concept, Ariely (2009: 292) said that "on one hand, we want to look in the mirror and feel good about ourselves...On the other hand, we're selfish, and we want to benefit from cheating...our flexible psychology allows us to act on both of them when we cheat just by a bit". Bitektine (2008: 76) mentioned the concept of a certain threshold or boundary when referring to social norms. The presence of some critical value of conformance with the expectations was then named "legitimacy threshold", which was recognized as the borderline between the socially accepted and the socially rejected behaviors. SSA instead differentiates between the fields of permissiveness and compliance. Where permissiveness does not imply socially accepted behaviors, but socially tolerated. Levine's (2005) "broken windows theory" is associated with the potential consequences of SSA suggesting that any small indication that something is amiss and not being taking care of sends signals about a lack of order, leading to lawlessness, and anarchy.

As individual attitudes and actions are related to the characteristics of its positions within an organization, a second construct, the Line of Impunity (LoI), "refers to the idea that certain ranks or positions in the social hierarchy entitle prerogatives or advantages, and that the power granted at those levels transcends the limits of control or law enforcement (such as in a tyranny). Overcoming the Line of Impunity consequently implies a rise in the ethical tolerance level (SSA), and hence a detachment from the customary ethical behaviors still demanded for lower ranks".

This concept is connected to the balance between risks and privileges. There are plenty of references related in one way or another to this concept, staring with Hofstede's (1984: 83) "power distance". Privileges and discrimination due to social rank were mentioned by Washington and Zajac (2005: 282), and Weber (1978: 305). The power of the elite was mentioned by Cohan, as the struggle for power, prestige and money characterized by ambition, elitism, talent, racial prejudice, impunity and perception of entitlement, where those engaged stayed unwilling or unable to realize their failures. The LoI represents a threshold that opens the door to foster manipulation, as there is perceived that different rules apply at higher echelons. Then, appealing to the field of politics serves to justify a disregard for the morality realm, as it is generally alleged that business decisions are built on strategy rather than on ethics. Even Porter (2012: B1), supports that corporate officials are rewarded for maximizing proceeds, not to behave ethically.

Academics like Brass (2002: 141) supported that power is an attribute of the position. Nevertheless, Nohria and Eccles (1992: 4) as well as Pryke (2005: 927) found a link between those positions and the actions, attitudes, and behaviors of its incumbents, which reaffirms Trevino's (1986: 603) assertion that both individual and situational variables have a role when dealing with ethical dilemmas. Fraedrich (1992: 14) sustained that individual's status within an organization could generate opportunities for unethical behaviors. In addition, it was observed a tendency in subordinates to pamper into self-deception by adopting the values, beliefs, attitudes, and behaviors of their superiors (Turnbull 1999: 129), or to accommodate their personal values to attain company goals (Carroll 1978). While 
opposing the LoI on moral grounds, Drucker (1986: 254) recognized its existence claiming that nobody should acquire exemption from ordinary rules due to their work or job. Academics like Stark (1993) recognized that a different kind of ethics is expected above certain hierarchy levels. Hiley (1987) found a link between power and values in organizational life. In his view, early behavioral studies as well as classical political theory are inadequate for understanding the concept of corporate power.

Solomon (1997) suggested that as a result of their grades, effort, and merit, a privileged class has appeared, being raised into power. Their success in corporate business made these people embrace a logic of social distance and inequality, standing as an out-of-touch manipulative and corrupt elite. Hayes (2012) argued that meritocracy has failed to fulfill its potential and that the social contract between the elites and ordinary citizens is wrecked. Brooks (2012) reaffirmed these concepts by asserting that the most capable elites have a leadership deficiency and they lack awareness of their social role, as the value of success has dethroned the value of virtue.

The Management Index (Bertelmann 2009) contains two dimensions, executive capacity and executive accountability, which in many cases seems to work in opposite directions. As one grows the other fades away. In his testimony before the U.S. Senate Committee on Banking, Housing, and Urban Affairs, Don Phillips (2004) -Managing Director of Morningstar, Inc.- stated that "the recent scandals make it abundantly clear that too many people in this industry is willing to forsake their responsibility in exchange for short-term personal profit. Sadly, these were not the acts of a few, low-level employees, but instead were violations of trust that took place at the highest levels, including company founders, CEOs, portfolio managers, and several current or former members of the Investment Company Institute's Board of Governors".

Levine (2005) referred to the propensity of some corporations to believe that they are so positive, so huge, so unbeatable, so much part of the modern civilization that they are not subject to the same examination by the public that makes any other company accountable. According to Davis et al. (2007) there is a general consensus among researchers and business analysts that the rising levels of executive rewards, along with the difficulties associated with monitoring top management activities, is creating an ethical dilemma. In view of the very few prosecutions of individuals resulted from the multiple fraud cases of the last times, Kelleher (2012: B1) speculated that the scarcity of criminal charges may cheer executives to test the legal boundaries. The absence of fear of punishment for ethical violations was described by Ross and Benson (1995: 350) as a cultural variable. Whilst Solomon (1997) talked about a sense of inequality and social distance embraced by corrupt and manipulative elites, Hayes (2012) blamed the meritocratic system mentioning that the social contract has been broken. Durham (2010) stated that many people are compelled by determination to succeed at all cost, often leading to unethical decisions. Stanford (2004) highlighted the existence of power abusers who frequently rule with unrestricted autonomy, as well as incidents of personal avarice among top executives, finding a positive correlation between the managerial level of authority and the potential for 
opportunistic actions, which reinforce the impression that unleashed conducts occur above the LoI. In this sense, Tiger Woods' extramarital affair provided a good example. Woods (2010) commented "I knew my actions were wrong, but I convinced myself the normal rules didn't apply... Money and fame made me believe I was entitled".

\section{Various Sets of Ethical Values and the Ethics Cube}

In order to depict how the various sets of ethical values operate, it was necessary to find a concept focused exclusively on the moral issue, independent of the traits of the moral agent or the organizational context. In this sense, Jones' (1991: 372) "moral intensity" captures the extent of issue-related moral imperative in a situation, including magnitude of consequences, social consensus, probability of effect, temporal immediacy, proximity, and concentration of effect.

The components of each set of ethical values are associated with the level of moral intensity assigned to certain factors. Figure 1 illustrates the case of four sets of ethical values. The horizontal axis represents the factors (desire, tolerance, ambition, apathy, irritation, resentment, and arrogance), the vertical axis specifies the levels of moral intensity. An analysis of the four sets of ethical values depicted in Figure 1 shows the differences among them. The highlights between individual ethics and social group ethics are that desire is constrained by the social group, while arrogance is boosted. Tolerance towards self and other's flaws and apathy increase in the social context. Moving to the professional ethics, desire and ambition, as well as irritation and resentment prevail, while there is also an increase in tolerance and arrogance. Finally, when considering the rank ethics, desire, ambition, irritation, and arrogance peak, while tolerance also increase, and apathy falls drastically. Overall, it is observed how these factors are pondered by each set of ethical values.

Along with the various sets of individual and group ethical values, other variables enter into the process of recognizing an ethical issue and acting upon it. Among them, personal interests, loyalties, and opportunity.

Personal interests denote private goals, feelings, and needs. From trivial to intricate, they comprise simplicities that can be obtained with no effort to aggressively pursued ambitions. Whatever biological or induced, associated with sensorial stimuli or with dreams, sometimes they have the muscle to bend, modify, and even replace ethical values. Ariely (2009: 293) expressed that "managing to see reality from a self-serving perspective is not an exclusive moral flaw, limited only to "bad people". It's a common human foible and is part of being human". 
Figure 1. Various Sets of Ethical Values

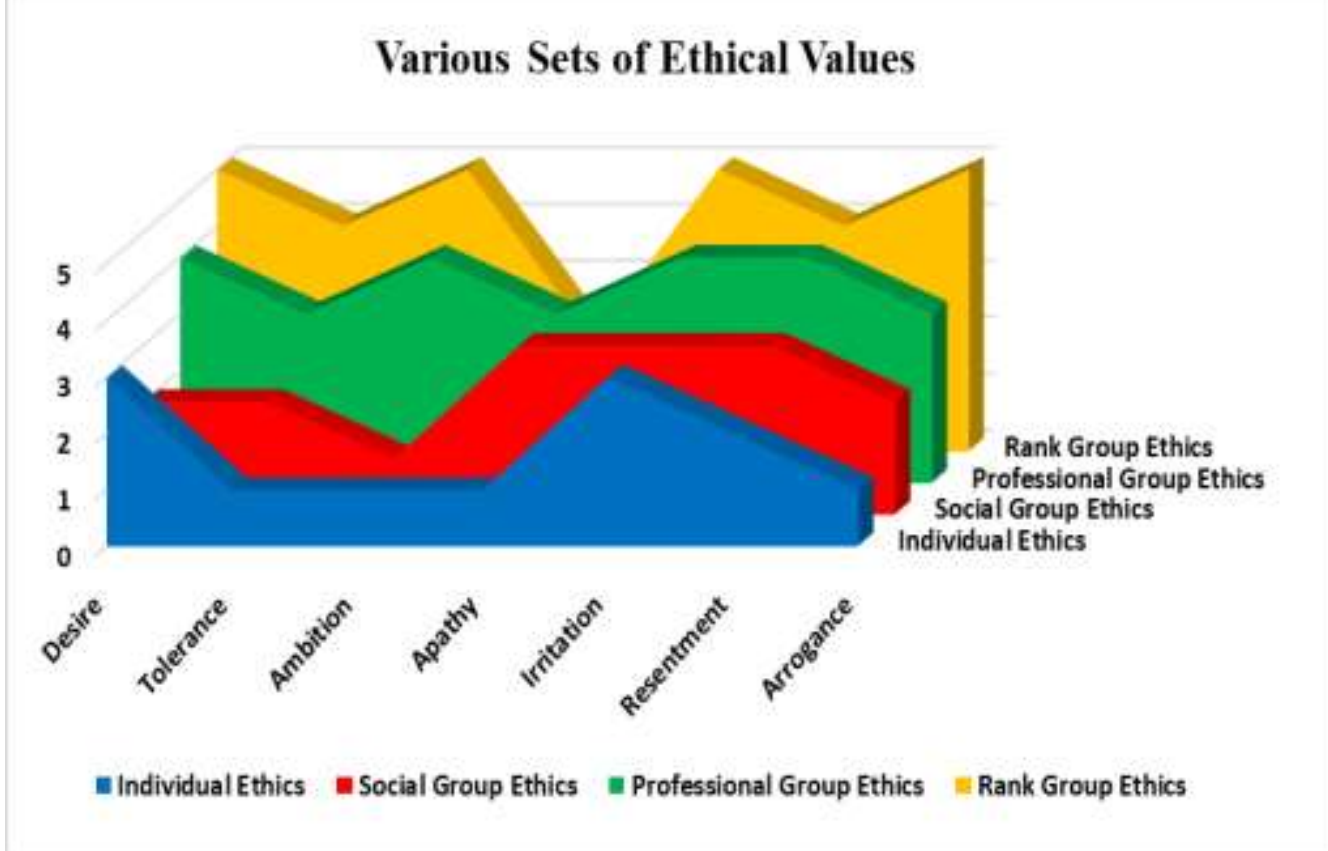

Source: Author.

Loyalties are strong feelings of allegiance, faithfulness, obedience, adherence, or devotion to an individual, a group, a cause, a country, or a faith. They are strengthened by social pressure and tough to modify. They could manifest in the form of herding (assuming other people's behavior), or differential association (attitudes favorable to the contravention of rules). Sometimes loyalties take precedence over ethical values and personal interests as they enjoy a higher level of devotedness.

Occasionally, people could undermine their values as the result of having the opportunity to take an advantage. In these cases, even truthful people could cheat. Trevino (1986: 608) warned that a lower moral judgment can be anticipated from managers in real job-related circumstances, than in reply to hypothetical predicaments. Ariely (2009: 202) said that "individuals are honest only to the extent that suit them".

Putting together the various sets of ethical values and the variables aforementioned, it is possible to build a tridimensional model capable to symbolize these components as well as its interactions. For instance, we could imagine a cube (like the Rubik's cube) where each face represents one of them. In such a way, one face symbolizes the attributes of the individual ethics, a second face denotes characteristics of social groups' ethics, as subsequent faces do with professional group ethics, personal interests, loyalties, and opportunity. In this way, for example, the professional group ethics face could display traits of efficiency, quality, cost consciousness, leadership, direction, risk propensity, and scrupulousness; while the opportunity face could display tendency to take advantage, unpredictability, unorthodox and hazardous courses of action, etc. 
In this theoretical state, each face displays solely its own attributes (imagine one color per face as in Figure 2). Nevertheless, as soon as ethical dilemmas surface, the cube becomes ruffled. In this condition, attributes of diverse faces are assorted irregularly, such that the faces lost their homogeneity. In this way, attributes of a particular set of ethical values (let's say professional ethics) are replaced by other traits that don't belong to it (Figure 3). It can be said that the shuffling process is stimulated by the SSA and the LoI (Lopez and Medina 2016).

Figure 2. Theoretical Ethical Cube

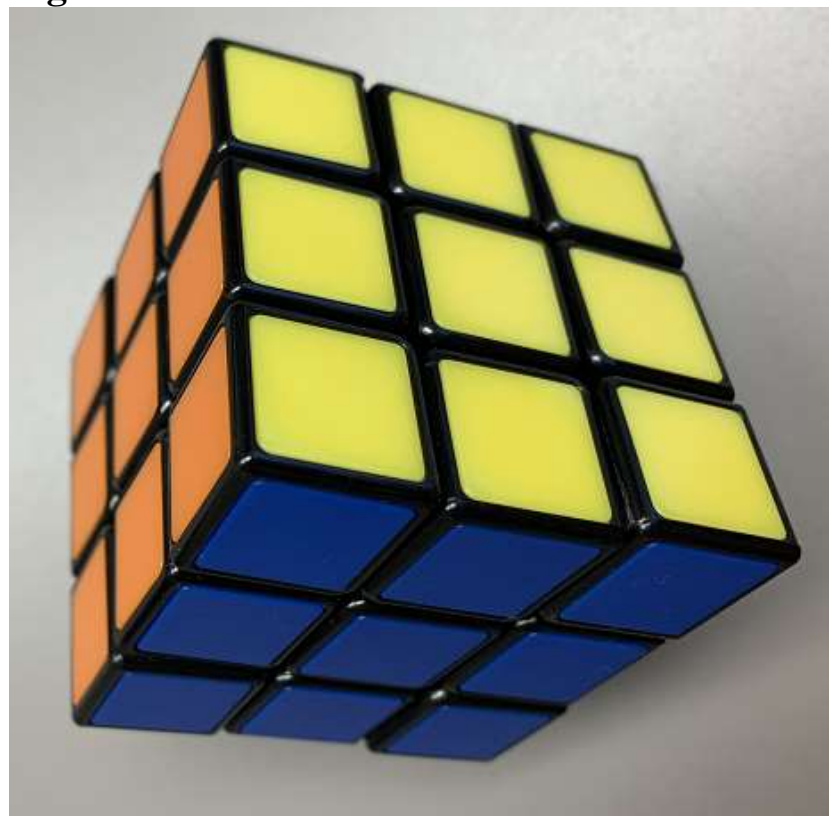

Source: Author

Figure 3. Shuffled Ethical Cube

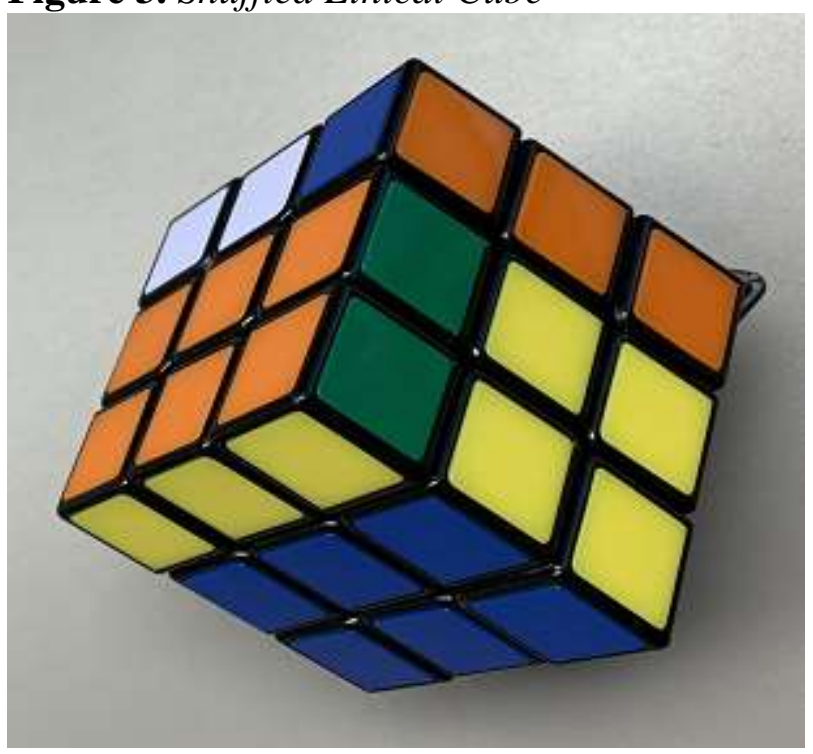

Source: Author 
As the Ethical Cube can be assumed to be a geometrical depiction of the governance system, it is worth reflecting about the contribution of the SSA and the LoI in this representation.

Three evidences should be considered:

1. An increase in either the size or the number of the SSA impacts negatively the quality of the governance system and vice versa.

2. When the LoI has been trespassed, the negative impact of the SSA upsurges. As a consequence, it can be said that the LoI affects the relationship between SSA and the governance system.

3. The context mediates in the way the SSA and the LoI affect the governance system. Reciprocally, the strength of the governance system reduces the incidence of the SSA, the chances of trespassing the LoI, impacting the context.

When there is a repetition of SSA, the professional group ethical posture is damaged as the confrontation approach towards unethical situations is worn out, and the monitoring and control attitude decays. Even the business objectives become blurred, ultimately reducing the chances of attaining them. The recurrence of SSA has a spiral effect that makes them grow over time, in such a way that something not tolerated at the early stages develops to be eventually tolerated. The SSA can be viewed as the ability to rotate the Ethics Cube's squares vertically.

The change in mentality that the perception of the LoI generates in the corporate ranks, facilitates the adoption of lax standards. Executives and managers that feel entitlement as legitimate are most likely lured into noncompliant conducts, which certainly involves a raise in the threshold associated with the SSA. The LoI can be viewed as the ability to rotate the Ethics Cube's squares horizontally. Additionally, the looseness or tightness of the Ethics Cube can be associated with context-related factors like anomie, cultural differences, scarceness-abundance, work environment, pressure and greed.

\section{Conclusions}

It was found that the SSA affects all the sets of ethical values, while the LoI affects principally the rank group ethics and in a lower degree the professional group ethics.

Governance systems change over time according to the prevailing ethical standards of the society. Whilst governance frames the permissible ethical behaviors, it is grounded on the ethical principles and expectations of the society in such a way that the relationship between ethical activities and governance is reciprocal and associated with the context where those activities take place. The expected ethical conducts appropriate for a profession, industry, or corporation, are the building blocks of the governance systems, which in turn will observe the outcomes of those sets of ethical values to avoid misconduct. Public perceptions, attitudes, and sentiments have changed. Consequently, achieving business 
objectives involves an alignment with the principal public beliefs. As such, trustworthiness is a fundamental element of the strategic management process. Conforming to societal ideals is the imperative that legitimizes business, as the ability to accomplish the social drive influences success. As social expectations are not merely associated with legal compliance but also with a correct attitude, accomplishing goals encompasses an alignment with community sentiments. Visions utterly molded in financial terms that relegates ethics will not last; they ought to go beyond boosting returns, sanctioning higher values.

Acknowledging that people operate with more than one set of ethical values, that they can be affected by situational factors, and that the presence of SSA and the LoI make it difficult to keep the ethical cube unshuffled, could be the first step toward defining a new and stronger business governance model, capable to resist deviant tendencies and to maintain an alignment with the social expectations. Working on the prevention and minimization of SSA and the LoI should be the paramount objective of a progressive governance that aims to keep all faces of the ethical cube pristine.

Looking into the future of ethics and governance, some aspirational directions of further analysis include a research into the dynamics of the components of the different sets of ethical values. An ideal development could be the depiction of a new and more sophisticated model that comprises all the variables that control the interactions among its parts.

\section{Acknowledgments}

My thanks to Dean Patrick Raines and Assistant Dean Stan York (Massey College of Business) at Belmont University for their continuous support of faculty scholarly advancement.

\section{References}

Ariely D (2009) Predictably Irrational. New York: Harper Collins.

Bandura A, Barbaranelli C, Caprara G, Pastorelli C (1996) Mechanisms of moral disengagement in the exercise of moral agency. Journal of Personality and Social Psychology 71(2): 365 .

Bertelmann (2009) Sustainable Governance Indicators: Policy Performance and Executive Capacity in the OECD. Gutersloh, Germany: Bertelmann Stiftung.

Bitektine A (2008) Legitimacy-based entry deterrence in inte-population competition. Corporate Reputation Review 11(1): 73-93.

Brass D (2002) Intraorganizational Power and Dependence. In JA Baum (ed) The Blackwell Companion to Organizations, 138-157. Malden: Blackwell Publications.

Brooks D (2012) Why Our Elites Stink? The New York Times: A23, (13 ${ }^{\text {th }}$ July 2012). Available at: https://www.nytimes.com/2012/07/13/opinion/brooks-why-our-elitesstink.html.

Carroll A (1978) Linking business ethics to behaviors in organizations. SAM Advanced Management Journal 43(3): 4-11.

Cohan WD (2014) The Price of Silence. New York: Scribner. 
Davis JL, Tyge Paine G, McMahan GC (2007) A few bad apples? scandalous behavior of mutual fund managers. Journal of Business Ethics 76(3): 319-334.

Drucker P (1986) Management: Tasks, Responsibilities, Practices. New York: Harper Collins Publishers.

Durham G (2010) Ethics: It Starts with you. Available at: http://www.pmi.org/About-Us/ Ethics/Ethics-It-Starts-With-You.aspx.

Ferrell OC, Fraederich J, Ferrell L (2019) Business Ethics: Ethical Decision Making and Cases, $\left(12^{\text {th }}\right.$ ed). Boston, MA: Cengage.

Fraedrich J (1992) Signs and signals of unethical behavior. Business Forum 17(2): 13-17.

Friedman M (1970) The Social Responsibility of Business is to Increase its Profits. The New York Times Sunday Magazine: 32-33.

Hayes C (2012) Twilight of the Elites: America after Meritocracy. New York: Crown Publishers.

Hiley D (1987) Power and values in corporate life. Journal of Business Ethics 6(5): 343353.

Hofstede G (1984) Cultural dimensions in management and planning. Asia Pacific Journal of Management 1(2): 81-99.

Jones TM (1991) Ethical decision making by individuals in organizations: an issuecontingent model. The Academy of Management Review 16(2): 366-395.

Kelleher D (2012) Corporate Fraud Cases Often Spare Individuals (8 August 2012). New York Times: B1.

Levine M (2005) Broken Windows, Broken Business: How the Smallest Remedies Reap the Biggest Rewards. New York: Business Plus.

Lopez E (2016) Influence of Ethical Behaviors in Corporate Governance. Saarbrucken, Germany: Lambert Academic Publishing.

Lopez E, Medina A (2016) Ethics and Governance in Project Management. Boca Raton, FL: CRC Press.

Ludlow P (2013) The Banality of Systemic Evil. The New York Times: 2.

Nohria N, Eccles RG (1992) Networks and Organizations. Boston: Harvard Business School Press.

Phillips D (2004). Testimony before the U.S. (25 February 2004). Senate Committee on Banking, Housing, and Urban Affairs.

Porter E (2012). The Spreading Scourge of Corporate Corruption (10 July 2012). The New York Times: B1.

Pryke S (2005) Towards a socila network theory of project governance. Construction Management and Economics 23(9): 927-939.

Renz P (2007) Project Governance: Implementing Corporate Governance and Business Ethics in Nonprofit Organizations. New York: Physica-Verlag.

Ross DL, Benson JA (1995). Cultural change in ethical redemption: a corporate case study. The Journal of Business Communications 32(4): 345-362.

Sekaran U (2003) Research Methods for Business: A Skill Building Approach, 4th ed. Hoboken, NJ: Wiley \& Sons.

Sobh R, Perry C (2006) Research design and data analysis in realism research. European Journal of Management 40(11-12): 1194-1209.

Solomon R (1997) It's Good Business. Lanham: Rowman \& Littlefield Publishers.

Stanford J (2004) Curing the ethical malaise in corporate America: organizational structure as the antidote. SAM Advanced Management Journal 69(3): 14-21.

Stark A (1993) What's the matter with business ethics? Harvard Business Review 71(3): $38-46$.

Sykes G, Matza D (1957) Techniques of neutralization: a theory of delinquency. American Sociological Review 22(6): 664-670. 
Trevino L (1986) Ethical decision making in organizations: a person-situation interactionist model. The Academy of Management Review 11(3): 601-617.

Turnbull S (1999) Emmotional labor in corporate change programmes. Human Resource Development International 2(2): 125-146.

Washington M, Zajac EJ (2005) Status evolution and competition: theory and evidence. Academy of Management Journal 48(2): 282-296.

Weber M (1978) Economy and Society: An Outline of Interpretive Sociology. Berkeley, CA: University of California Press.

Woods T (2010) Tiger Woods Admits Thought Entitled. New York Daily News - Entertainment. Available at: http:-thought/www.nydailynews.com/entertainment/gossip/tige r-woods-admits-thought-entitled-doesnt-deserve-forgiveness-article-1.197884\#ixzz2 Vol9pbTa. 